\title{
A STEP TOWARD EARLY PHONEMIC AWARENESS: THE EFFECTS OF THE TURTLE TALK TRAINING
}

\author{
Philip B. GOUGH ${ }^{1)}$ and Chang H. LEE ${ }^{2)}$ \\ ${ }^{1)}$ University of Texas at Austin, U.S.A. and ${ }^{2)}$ Pusan National University, Korea
}

\begin{abstract}
Phonemic awareness has been known as the most important variable for developing reading skills. Although various training curricula and programs were developed in order to cultivate the phonemic awareness, this study introduces a new phonemic awareness curriculum, called Tturtletalk training program. The principle of this program in learning is pronouncing each letter of a word as slowly as possible in reading, making a child focus on each phoneme of a word. The children trained by this program have shown better phonemic awareness test score than those trained by a current reading training curriculum. The implication of these results and the prospect of the Turtletalk program were discussed.
\end{abstract}

Key words: phonemic awareness, Turtle Talk training, children, reading acquisition

Research has clearly demonstrated that phonemic awareness plays an important role in learning to read an alphabetic language like English or Spanish. First, the presence of phonemic awareness on school entry predicts subsequent reading achievement better than parental reading, socioeconomic status, or even intelligence (e.g., Share, Jorm, Maclean \& Matthews, 1984). Second, the majority of reading disabled children exhibit a lack (or deficiency) in phonemic awareness. Third, more than 20 studies have demonstrated that teaching phonemic awareness to the child increases reading achievement (e.g., Ehri, Nunes, Willows, Schuster, Yaghoub-Zadeh \& Shanahan, 2001; Lohman \& Fucci, 2002; Lundberg, Frost \& Petersen, 1988).

Why is phonemic awareness so important? In our view (Gough, Juel \& Griffith, 1992), it is because it is necessary for mastery of the cipher. By the cipher we mean the complex system of letter-phoneme correspondences of our orthography. Why is the cipher so important? It is important for two reasons. First, it gives the beginning reader a way of recognizing novel words. The beginning reader constantly encounters novel words. For the most part, they are words that are already known to the child in their spoken form. Context will undoubtedly help the child recognize some of these. But context is a false friend, for our research has shown that it will help you most with common, short, words, like function words, where you don't need help. But it will help

The authors wish to thank Youngseok, Lim, Leslie Luciano, Sebastian Wren, Jennnifer Watts, Nicole Deneen-Bell, and Mark Cochran for their assistance in carrying out the study.

Correspondence concerning this article should be addressed to: Philip B. Gough, Department of Psychology, University of Texas at Austin, Austin, TX, 78712, U. S. A., e-mail: gough@psy.utexas.edu, or to Chang Lee, Department of Psychology, Pusan National University, 30 Changjeon-dong, Keumjeong-ku, Pusan 609-735, Korea, e-mail: chleehoan@pusan.ac.kr 
you least with infrequent, long words, where you most need it. Second, it helps the reader's memory problem. While a few function words occur constantly, most nouns, verbs, and adjectives occur only rarely; the modal frequency of most content words in any text is one. Thus most words are only rarely enountered, so remembering their visual forms is very difficult. But if the child is able to decipher the printed word into its phonological form, they need remember only what is unique to that word.

There is abundant evidence that mastery of the cipher is crucial to skilled reading (Gough, 1996). The best indication of mastery of the cipher is the ability to read pseudowords. This ability correlates .9 or better with measures of reading comprehension in the early grades (Hoover \& Gough, 1990). Its absence has become a hallmark of the dyslexic (Rack, Snowling \& Olson, 1992).

Phonics instruction aims to implant the cipher. Sometimes it does. But for too many, it fails (Juel, Griffith \& Gough, 1986). The reason seems to be the lack of phonemic awareness. Growing recognition of the importance of phonemic awareness has led to the development of a number of training programs (e.g., Adams, Foorman, Lundberg \& Beeler, 1998; Blachman, Ball, Black \& Tangel, 1994; Byrne \& Fielding-Barnsley, 1991). But how effective are these programs? Each of them has found significant effects, showing that a trained group performs better than a control. But none of them has come close to bringing every child to full phonemic awareness. There is clearly room for improvement. These programs are also very time-consuming. This would not matter if we could devote unlimited time to them. For example, as part of the kindergarten curriculum, they should prove very effective. But in most States in U.S.A., only a little more than half of the children attend kindergarten. What are we to do with the other half? We cannot devote the entire first grade to phonemic awareness.

The aim of the present research was to see if we could develop ways of awakening phonemic awareness more quickly. To this end, we designed two new curricula, to be delivered in 10-15 minutes per day for 20 days. Two basic principles guided both designs. First, we thought it important to teach only those aspects of phonemic awareness which directly bear on reading and spelling. Thus we devoted no time to rhyme, deletion, or oddity. We also decided to spend no time on blending. A word about these decisions is in order. We eliminated rhyme because rhyme is at best a precursor of phonemic awareness; it probably plays no role in the reading process. It certainly is important for a child to grasp the concept of rhyme. But we see no reason to believe that it is essential to phonemic awareness. We eliminated deletion in the belief that it, too, plays no role in reading or writing. Clearly, the child who can delete an initial, medial, or final phoneme has a high degree of phonemic awareness. But we are not convinced that this skill is essential to reading and writing. So far as we can see, it is useful only for Pig Latin. Oddity, too, is a task which clearly depends on some level of phonological awareness. But it seems clear to us that it does not require full segmentation, nor does it otherwise figure in reading or writing. More controversially, we decided to eliminate blending. Many scholars hold that blending is a crucial component of phonemic awareness. We are not convinced of this. As we see it, blending plays an important role in phonics. That is, to effectively use phonics, having "sounded out" a string of letters, the child must be able to 
blend those separate phonemes into a word. But we believe that a child who is sounding out and blending a word is not deciphering; they are using phonics as a tool to identify a word when there is no other way of doing so.

Why do we say this? We argue that there are important differences between the rules taught in phonics and the rules which the child must internalize to become a skilled decoder(Gough et al., 1992). We call the latter the cipher. The rules of phonics are (in the main) context-free; the rules of the cipher are (save one) context sensitive. The rules of phonics number 80-120; the rules of the cipher number in the thousands. Finally, the rules of phonics are explicit and conscious; the rules of the cipher are mostly implicit and unconscious. Cipher includes most inconsistent and irregular words (e.g., pint, bowl) that the phonic can not be applied.

Our second principle was based on our conviction that phonemic awareness is not unitary, an ability which the child either has or doesn't have. Instead, we believe that it develops in stages, that distinct levels of phonemic awareness can be identified and measured. Given this latter belief, we aimed at that level of phonemic awareness which we deemed to be necessary for reading. This we take to be full segmentation of monosyllabic words. We see segmentation as important for two reasons. First, it is essential for invented (phonemic) spelling. Second, Yopp (1992) has shown that full segmentation is a better predictor of later reading achievement than the other nine tasks she measured. Given these assumptions, we decided to take two approaches to full segmentation. One curriculum, which we called Turtletalk, attempted to "cut to the chase," and aim at full segmentation from the beginning. The other curriculum approached full segmentation in steps. The children spent a week attempting to isolate initial phonemes, a second week on final phonemes, and a third on medial phonemes, before attempting Turtletalk in the final week. We dubbed this the Stepwise Curriculum.

To assess the effectiveness of the two curricula, we implemented each in approximately 25 kindergarten classrooms. We pretested and posttested all children in these classrooms. We also pre- and posttested children in 29 control classrooms, whose teachers received no instruction from us. (As we shall see, several of these "control" teachers began to use our curricula and materials, and others reported working on phonemic awareness in their reading readiness curriculum.)

\section{TraINING}

\section{METHOD}

We began by assessing the phonemic awareness of all children in the 78 classrooms. Each child was assessed individually by a research assistant, using the questionnaires (English and Spanish) presented in Appendices 1. Each questionnaire consists of six phonemic awareness questions, interspersed with six filler questions chosen to be easy for kindergartners. The phonemic awareness questions assessed the child's ability to isolate an initial phoneme, a final phoneme, and a medial phoneme, to fully segment a monosyllabic word, to provide a rhyme, and to identify a phoneme shared by two words. Each question gave the child five examples of each task. For example, the tester would say to the child, "I'm going to say five words that all begin with the same phoneme: man, milk, money, mend, march. What is the first phoneme in march?" 
We decided to use this questionnaire, rather than a standardized instrument with documented reliability and validity (e.g., the Test of Phonemic Awareness, or TOPA; Torgesen \& Bryant, 1996) for two reasons. The major one is that instruments like the TOPA assess only one or two levels of phonemic awareness (in the case of the TOPA, isolation of initial and final phonemes.) We have known at least since Stanovich, Cunningham \& Cramer (1984) that there are various degrees of phonemic awareness: a child may pass some tests of phonemic awareness and fail others. For example, Yopp (1988) found that 59 percent of 96 kindergarteners could isolate an initial phoneme, but only 26 percent could delete the initial phoneme and generate the remaining phonemes. A better alternative, then, would have been to use a battery of tests, a la Stanovich, et al (1984) or Yopp (1988). The problem with such batteries are twofold. First, they are very time-consuming, all but impossible to use in the assessment of large numbers of children. Secondly, given the time they spend, it is seems quite possible that they amount to instruction, resulting in iatrogenic phonemic awareness.

We found evidence that the items in the questionnaire approximated a Guttman scale (i.e., a scale in which a testee's score tells you exactly which items she passed and which items she failed.) For example, about half of the children could isolate an initial phoneme. Only a quarter could isolate a final phoneme. But the children who could isolate the final phoneme were a proper subset of those who could isolate the initial phoneme. No child who could not isolate an initial could isolate a final. Thus initial phoneme isolation appears to be necessary, but not sufficient for final phoneme isolation, and final phoneme isolation appears to be sufficient but not necessary for initial phoneme isolation. Thus we decided to ask each child whether they could isolate initial, final and medial phonemes and fully segment a monosyllable into phonemes. We also decided to ask whether they could provide a rhyme, and whether they could identify the phoneme common to two words, in hopes of seeing how these abilities related to the "segmentation scale." Our hypothesis is that a child must reach the top of this scale, i.e., full segmentation, in order to master the cipher. This, then, was the goal of our training.

In separate two-hour workshops, the Turtletalk curriculum was presented to 24 teachers, and the Stepwise curriculum to 25 teachers. In each case, the importance and role of phonemic awareness were discussed. Materials for the first week were distributed.

Both curricula were very simple. To introduce Turtletalk, it was suggested that the teacher ask the children what they know about turtles. In discussing turtles, the fact that they move very slowly will arise. Then the teacher should ask the children if turtles can talk. When they say no, the teacher should say that if they did talk, they would also talk very slowly. So a turtle might say turtle like this: "T-R-T-L" (uttering the phonemes, not the letter names, i.e., /t-r-t-1/), pausing between phonemes. Then she will ask the children how a turtle would say X (e.g., the child's name). The teachers were provided with a list of words for each day. The Stepwise curriculum spent a week isolating initial phonemes, a second week isolating final phonemes, and a third extracting medial phonemes. In the last week, Turtletalk was introduced.

The week before the teachers received this instruction, undergraduate and graduate research assistants individually administered a phonemic awareness questionnaire to each of the children in the classrooms of these teachers, as well as each of the children in 29 control classrooms.

The teacher was asked to devote 10-15 minutes per day to the curriculum, and to provide feedback at the end of the week as to the problems she encountered. The feedback was the subjective judgement on the curriculum such as the difficulty of training words, how the children performed and so on. On the basis of this feedback, the materials for the subsequent week were constructed and was provided to the teacher. After the teacher had completed 20 days of training, each child was post-tested by the same tester who had pretested the child. The post-test (Appendices 2) took the same form as the pre-test with two exceptions. First, the filler questions were now more challenging. (We sought to obtain some descriptive data about the distribution of knowledge in kindergartners.) Second, four additional questions asking for segmentation of words containing consonant clusters were included. Finally, each teacher was asked to fill out a questionnaire (Appendices 3 and 4) regarding their participation and their evaluation of the curriculum.

\section{RESULTS}

We were able to obtain complete pre-test data on 1147 children, 410 in the Control Group, 368 in the Step Group, and 369 in the Turtletalk Group. The proportion of children 
in all three groups who passed each of the six phonemic awareness items is presented in Figure 1. Two things are worth noting in these data. Some (e.g., (Allington, 1997)) believe that phonemic awareness will develop spontaneously, i.e, without instruction. The present data suggest that while some level of phonemic awareness may well develop spontaneously (or in response to parental and school activities) that level is quite low in late (March) kindergarten. Roughly .60 of the kindergartners were able to isolate an initial phoneme. But only a third could isolate a final phoneme, and even fewer (.22) could isolate a medial phoneme. Still less (.19) could fully segment a monosyllable. Rhyme proved to be easier; nearly half (.47) could provide a rhyme. About .40 could identify a phoneme common to two words. Our data indicate that few kindergartners have full phonemic awareness (defined as full segmentation) by March, and far more have none at all.

Secondly, as luck would have it, our experimental and control groups did not begin the study with equal amounts of phonemic awareness. The proportion of children in each of the three groups correctly answering each of the six phonemic awareness questions is presented in Figure 2. Analyses of variance revealed significant differences between the groups on every one of the six phonemic awareness questions. Specific contrasts showed that in each case, the Control Group outscored the two experimental groups, which did not differ significantly.

We turn now to evaluate the effects of our intervention. As noted above, we obtained

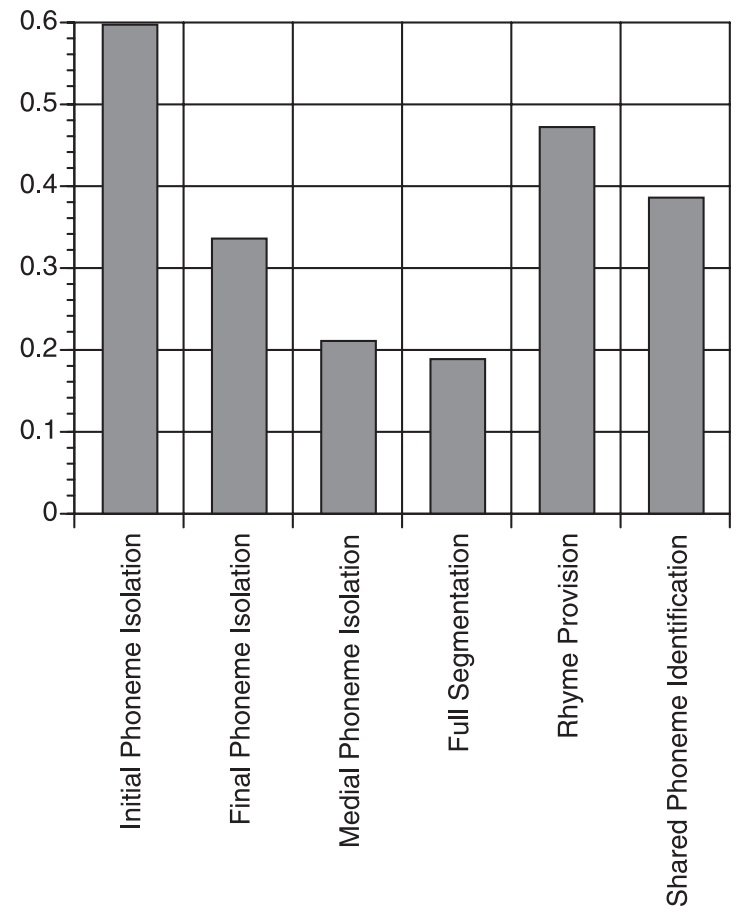

Fig. 1. Proportion of children in all three groups answering each question in the pre-test. 

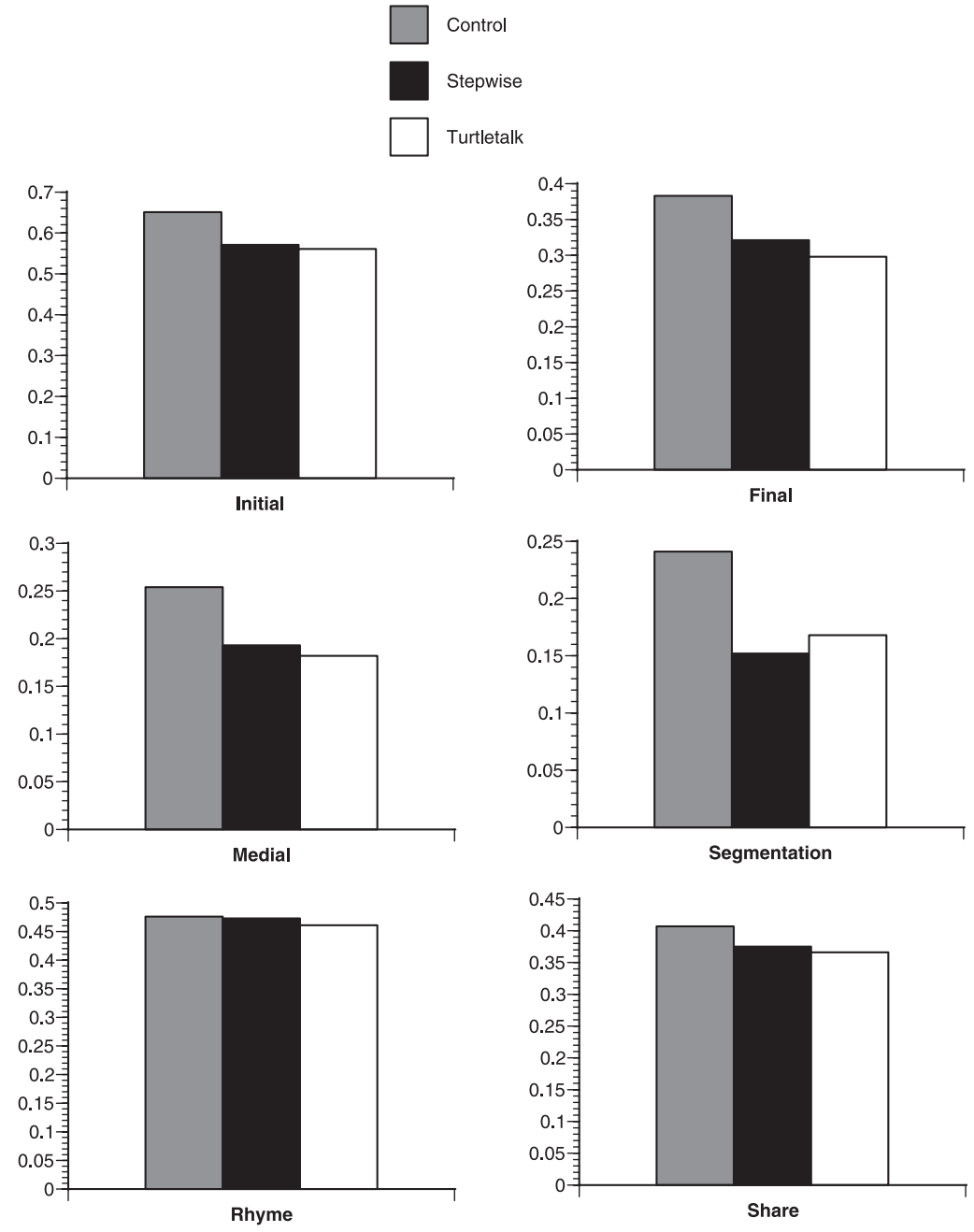

Fig. 2. Proportion of children in each group passing each item.

complete pre- and post-test data on 1147 children, 410 in the Control Group, 368 in the Stepwise Group, and 369 in the Turtletalk Group. Mean performance on the pre- and post-tests are presented in Figure 3 for each of the three groups.

Initial phoneme. Taken collectively, all three groups improved from pre- to posttesting $\left(F_{1,1144}=359.045 ; p>.001\right)$. But a significant interaction $\left(F_{2,1144}=8.974, p<.001\right)$ indicated that they did not improve equally. Specifc contrasts of the gain scores (Fisher's PLSD) revealed that the Control Group's gain (.056) was signifcantly less than both the Stepwise Group's (.193) and the Turtletalk Group (.179).

Final phoneme. Again, all three Groups gained from pre- to post-test $\left(F_{2,1144}=2.412\right.$, $p<.10$ ), though the overall gain was only marginally significant. Similarly, a modest 

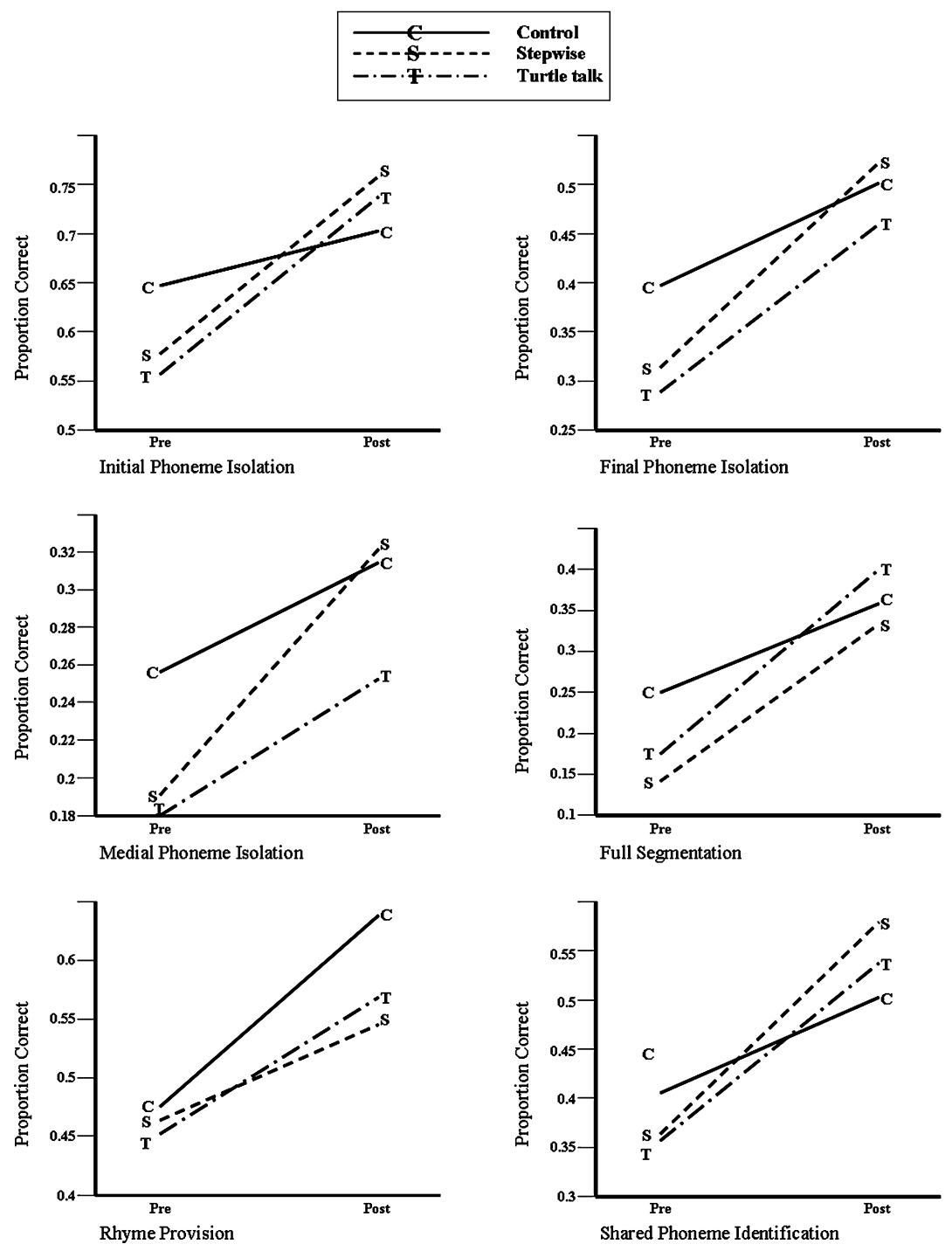

Fig. 3. Pre- and post-test scores for each group

interaction was obtained $\left(F_{2,1144}=2.531, p<.10\right)$ suggesting that the Stepwise and Turtletalk Groups gained more (.204 and .163, respectively) than did the Control Group (.122). However, Fisher's PLSD revealed that only the Stepwise Group gained significantly more than the Control.

Medial Phoneme. The effect of training on medial phoneme isolation was minimal $\left(F_{1,1144}=3.21, p<.05\right)$. The Control Group gained .061, while the Stepwise and Turtletalk Groups gained slightly more (.133 and .079). The interaction was not significant $\left(F_{2,1144}=2.038, p=.13\right)$. 
Full Segmentation. Full segmentation tells a different story. The Control Group increased from .24 to .35 , a little less than 50 percent. But the number of children who could fully segment a monosyllabic word more than doubled in the Stepwise Curriculum (.15 to .33), and the Turtletalk Group improved even more (.17 to .38). This interaction proved highly significant $\left(F_{1,1144}=4.71, p<.01\right)$. Fisher's PLSD revealed that both the Stepwise and Turtletalk Groups gained significantly more than the Control Group.

Rhyme. The results with Rhyme Provision were surprising, for the Control Group increased more $(.48$ to, 61$)$ than either the Stepwise Group $(.47$ to .54$)$ or the Turtletalk Group (.46 to .56). However the differences of improvement between Turtletalk group (.10) and the control group (.13) were minimal.

Shared Phoneme Identification. All three groups significantly increased their ability to identify a shared phoneme $\left(F_{1,1144}=4.71, p<.01\right)$ But while the Stepwise $(.38$ to .58$)$ and Turtletalk (.37 to .55$)$ gained significantly more than the Control Group (.41 to .51$)$, the differences only approached significance $\left(F_{2,1144}=2.97, p<.06\right)$.

It is interesting that our large Control Group showed significant improvement on almost all of the tasks, doing especially well on Rhyme Provision. As noted earlier, they began the study with a higher level of phonemic awareness than the two experimental groups, but they did not show as much improvement. Nevertheless, they did show significant improvement.

This might be taken to support the view of Allington (1997) and others that children will acquire phonemic awareness without intervention. But a post-study questionnaire and interviews with a number of Control teachers revealed that they had not been "true" controls. Many reported that they had engaged in phonemic awareness training as part of reading readiness instruction; indeed, several reported that they had co-opted the materials being used by the experimental teachers. As a result, many of our control classes received phonemic awareness training resembling that of our experimental groups.

\section{DISCUSSION}

We find our results very encouraging. In the first place, analysis of our phonemic awareness data provides further evidence that we may be able to develop a Guttman Scale of phonemic awareness. Furthermore, the data suggest that some of the measures that researchers have used to measure phonemic awareness may not be valid, or at least sensitive to the most important aspect of phonemic awareness. For instance, our data indicate that rhyme provision is only tangential to the central dimension of phonemic awareness, i.e., segmentation, as is identification of a shared phoneme.

Secondly, our results indicate that many children can reach full segmentation without months of pretraining; for these children at least, one can "cut to the chase."

A skeptic might argue that all we have done is reconfirm the well-established finding that time on task (TOT) is a primary determinant of achievement. The children taught to segment learned to segment; the children taught to isolate initial, final, and medial phonemes learned to do that. Our response would be that this is just the point. What we 
have shown is that many children do not need months of listening games, rhyming, or clapping syllables to reach full segmentation. Instead, one can teach segmentation directly.

Would more children have achieved full segmentation if they had engaged in such activities? Perhaps. That is an empirical question which we would like to answer in further research. But it seems just at least as likely that more would have achieved full segmentation if they had just engaged in Turtletalk longer.

We believe the Turtletalk curriculum merits further development. We learned that it need not be employed as a scripted lesson plan. Instead, several teachers reported that they used it as a "sponge" activity. Importantly, Turtletalk is closer to a game than to a drill. Many children found Turtletalk entertaining, and spontaneously asked to play it. It can be played with any word, including the children's names and other words of intrinsic interest to the child. It is obviously not "meaningful"; phonemes have no meaning. But many children enjoyed playing it nonetheless.

Nevertheless, we are not satisfied with our results. Our two curricula did succeed in more than doubling the number of children who could fully segment, and we achieved partial success with many others. But we fell well short of bringing all children to full segmentation. Our future research will explore ways of improving our curricula.

Another important topic for future research is the bilingual. As we noted, we were unprepared for the number of bilingual classrooms that participated in the study, and we were unable to provide materials for this group after the first week. The bilingual teachers thus proceeded on their own; seemingly, they did very well, for we could find no difference between the gains shown by the bilingual classes and the English only classes.

The central conclusion we would draw from this research is that it is possible to teach phonemic awareness more quickly than other training programs have done. Compare, for example, our curricula with that published by Adams et al. (1998), based on the phonemic awareness training program introduced by Lundberg et al. (1988). The authors suggest that the teacher spend 26 weeks playing listening games, rhyming, learning about words and sentences, segmenting words into syllables, and isolating initial and final sounds before beginning full segmentation training. These activities may have intrinsic merit. But what our results suggest is that if your goal is full segmentation (as we think it ought to be), there is no need to devote 26 weeks (half a year) to these preliminary activities

The main limitation of the current study is that the control in this study might not be a real control. The control group scored better that the training groups on the pre-test. Thus the speed of improvement could get slow as one's score increased as is a sigmoid curve. In addition, we faild to control each teacher's activities, and some school teachers at control classes gave children the instuctions similar to phonemic awareness training. Thus, the effect of training become equivocal. Finally, there was weak comparison between the Turtle Talk training and the other training methods, such as stepwise training. The design of the current study was not focused on the comparision between the two training methods, leaving out related specific analyses.

Our research also leaves many unanswered questions. First, there is the question of 
how to achieve better results. While we were able, in five hours of instruction, to more than double the number of children who could fully segment, neither curriculum brought more than half of the children to this level. A number of the teachers suggested to us that more of the children would have caught on if we were just patient enough. We would like to explore that possibility by introducing Turtletalk early in kindergarten and studying the growth of segmentation. Second, there is the question of why of our curricula failed so many children. What stands in the way of a child acquiring phonemic awareness?

We conclude that we have demonstrated that many children can be led directly to phonemic awareness, without months of pretraining. We belive that many of the phonemic awareness activities employed in other training programs are superfluous, and that more research should be devoted to faster, more efficient instructional techniques like Turtletalk.

\section{REFERENCES}

Adams, M. J., Foorman, B. R., Lundberg, I., \& Beeler, T. 1998. Phonemic awareness in young children. Baltimore, MD: Paul H. Brookes Publishing Co.

Allington, R. L. 1997. Overselling phonics. Reading Today, 15, 15-16.

Blachman, B. A., Ball, E. W., Black, R. S., \& Tangel, D. M. 1994. Kindergarten teachers develop phoneme awareness in low-income, inner-city classrooms. Reading and Writing, 6, 1-18.

Byrne, B., \& Fielding-Barnsley, R. 1991. Sound foundations. Sydney: Peter Leyden Educational Publishers.

Ehri, L. C., Nunes, S. R., Willows, D. M., Schuster, B. V., Yaghoub-Zadeh, Z., \& Shanahan, T. 2001. Phonemic awareness instruction helps children learn to read: Evidence from the national reading panel's meta-analysis., Reading Research Quarterly, 36, 250-287.

Gough, P. B. 1996. How children learn to read and why they fail. Annals of Dyslexia, 46, 3-20.

Gough, P. B., Juel, C., \& Griffith, P. L. 1992. Reading, spelling, and the orthographic cipher. In P. B. Gough, L. C. Ehri, \& R. Treiman (Eds.), Reading acquisition, (pp. 35-48). Hillsdale, NJ: Lawrence Erlbaum Associates.

Hoover, W. A., \& Gough, P. B. 1990. The simple view of reading. Reading and Writing, 2, 127-160.

Juel, C., Griffith, P. L., \& Gough, P. B. 1986. Acquisition of literacy: A longitudinal study of children in first and second grade. Journal of Educational Psychology, 78, 243-255.

Lohman, P., \& Fucci, D. 2002. Relationship between phonemic and lingual awareness. Perceptual \& Motor Skills, 94, 860-866.

Lundberg, I., Frost, J., \& Petersen, O. 1988. Effects of an extensive program for stimulating phonological awareness in preschool children. Reading Research Quarterly, 23, 263-284.

Rack, J. P., Snowling, M. J., \& Olson, R. K. 1992. The nonword reading deficit in developmental dyslexia: A review. Reading Research Quarterly, 27, 28-53.

Share, D. L., Jorm, A. F., Maclean, R., \& Matthews, R. 1984. Sources of individual differences in reading acquisition. Journal of Educational Psychology, 76, 1309-1324.

Stanovich, K. E., Cunningham, A. E., \& Cramer, B. R. 1984. Assessing phonological awareness in kindergarten children: Issues of task comparability. Journal of Experimental Child Psychology, 38, 175-190.

Torgesen, J. K., \& Bryant, P. E. 1996. Test of phonemic awareness (TOPA), Austin, TX: Pro-Ed., U.S.A.

Yopp, H. K. 1988. The validity and reliability of phonemic awareness tests. Reading Research Quarterly, 23, 159-177.

Yopp, H. K. 1992. A longitudinal study of the relationship between phonemic awareness and reading and spelling achievement. Paper presented at the A.E.R.A., San Francisco, U.S.A. 
Appendix 1. Phonemic awareness pretest (English version)

PHONEMIC AWARENESS

Student

Birth

Gender

Date

97

Schoo Ethnicity

Tester

Here is a row of ducks. They're all going to the lake.

Which is the first duck? Write an F in the duck to which the child points.

Which is the last duck? Write an L in the duck to which the child points

Which is the middle duck? Write an M in the duck to which the child points

0 . What's the longest word you can think of?

1. Do you know what color a fire truck is?

2. I'm going to say five words that all begin with the same sound: man, milk, money, mend, march. What's the first sound in march?

3. What does a cow say?

4. Now I'm going to say five words that all end with the same sound: fun, hen, plan, spin, moon. What's the last sound in moon?

5. How many legs does a dog have?

6. Now I'm going to say five words that all have the same sound in the middle: melon, pilot, color, bullet, police. Can you tell me what the middle sound is in police?

7. What does a monkey eat?

8. Cat rhymes with hat. House rhymes with mouse. Hand rhymes with band. Moon rhymes with soon. Red rhymes with bed. Can you tell me a word that rhymes with ball?

9. Can a cat fly?

10. Did you know that every word in our language can be broken into little sounds called phonemes? I can break any word into its phonemes, like this: DOG is D-AW-G. MISS is M-IH-SS. BOOK is B-OO-K. NOSE is N-OH-Z. CAT IS K-A-T. Can you break SUN into its phonemes?

11. The words CAT and TIME share the phoneme /t/. The words SUN and MISS share the phoneme $/ \mathrm{s} /$. The words MOON and HAM share the phoneme $/ \mathrm{m} /$. The words RUBBER and BOOK share the phoneme $/ \mathrm{b} /$ The words GUM and BIG share the phoneme $/ \mathrm{g} /$. Can you tell me the phoneme that the words $\mathrm{ZOO}$ and RAZOR share?

Appendix 2. Phonemic awareness post-test (English version)

\section{PHONEMIC AWARENESS SPRING}

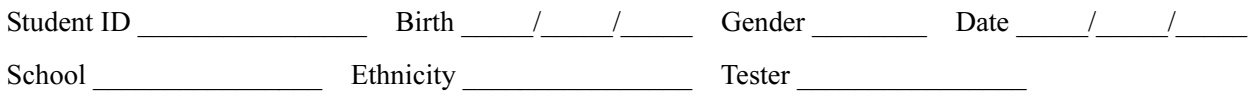

1. "Tell me the longest word you can think of."

2. "Can you count to ten?"

3. "I'm going to say five words that all begin with the same sound: moon, mouse, milk, mop, match. Can you tell me what the first sound of match is?"

4. "Can you recite the alphabet for me?" 
5. "Now I'm going to say five words that all end with the same sound: tin, fun, rain, thin, sun. What's the last sound in sun?"

6. "How many sides does a triangle have?"

7. "Now I'm going to say five words that all have the same sound in the middle: yellow, melon, balloon, color, hollow. Can you tell me what the middle sound is in hollow?"

8. "What does sad mean?"

9. "Cat rhymes with hat. Goose rhymes with loose. Yard rhymes with card. Soon rhymes with tune. Switch rhymes with witch. Can you tell me a word that rhymes with yell?"

10. "What's the tallest mountain on Earth?"

11. "Every word in our language can be broken into little sounds called phonemes. I can break a word into phonemes like this: moon is made of MM-OO-NN. Fish is made of FF-II-SHH. Cheese is made of CHEE-ZZ. Can you break sun into phonemes?

12. "Can you break the word land into phonemes?"

13. "Can you break the word salt into phonemes?"

14. "Can you break the word block into phonemes?"

15. "Can you break the word grass into phonemes?"

16. "The words moon and gum share the phoneme $/ \mathrm{m} /$. The words sun and miss share the phoneme /s/. The words cool and back share the phoneme $/ \mathrm{k} /$. The words nut and moon share the phoneme $/ \mathrm{n} / \mathrm{The}$ words gum and big share the phoneme $/ \mathrm{g} /$. Can you tell me the phoneme that the words zoo and razor share?

Appendix 3. Teacher questionaire (Turtletalk training group)

\section{TEACHER QUESTIONNAIRE}

Teacher School

1. How many students were in your class?

2. How many spoke Spanish?

3. How many were native speakers of another foreign language?

4. On a scale from one (wealthy) to seven (poor), where would you place your average student?

5. How many African-American students did youi have?

6. How many Hispanic students did you have?

7. How many Asian-American students did you have?

8. How many days did you implement our phonemic awareness curriculum?

9. Did you work on your children's phonemic awareness after the 20 days?

10. How many minutes per day (on average) did you engage in this activity?

11. How faithfully did you follow the suggested sequence? Please assign a rating from one (not at all) to seven ("religiously").

12. Did you add anything to the prescribed curriculum? Is so, what?

13. How successful would you judge the curriculum to have been? Please assign a number from one (totally unsuccessful) to seven (very successful).

14. How many of your children reached full segmentation? 
15. What did you find wrong with the curriculum? Please answer on the reverse.

16. Would you recommend this curriculum to other teachers?

17. Do you think the curriculum was worth while?

18. Do you think your children will learn to read better because of the curriculum?

19. How did you distribute your "attention." Please assign a number from one (on the students having most difficulty) to seven (evenly)

20. Did you teach your children the alphabet?

Appendix 4. Teacher questionaire (Control)

\section{TEACHER QUESTIONNAIRE C}

Teacher School

1. How many students were in your class?

2. How many spoke Spanish?

3. How many were native speakers of a foreign language other than Spanish?

4. On a scale from one (wealthy) to seven (poor), where would you place your average student?

5. How many of your students were African-American?

6. How many of your students were Hispanic?

7. How many of your students were Asian-American

8. Did you teach your children the alphabet?

9. Have you heard of phonemic awareness?

10. How would you define it? Please answer on the reverse side of this page.

11. Did you work on your children's phonemic awareness at all this spring? Please choose a number from one (never) to seven (every day).

12. If you did, how many minutes per day (on average) did you work on your children's phonemic awareness?

13. Exactly what did you do? 